\title{
Assessment of the Somatic Health Level of Schoolchildren Studying in Grades 2-6
}

\author{
Shakhanova A.V.* Silantiev M.N. Chelyshkova T.V. Grechishkina S.S.
}

\author{
Adygea State University, Maykop, Russia \\ *Corresponding author. Email: S4209691@yandex.ru
}

\begin{abstract}
The authors evaluated the level of physical health of students in grades 2-6 based on a comprehensive analysis of indicators of the functional state of the body. The study made it possible to identify among students a high-risk group for the formation of diseases at certain stages of training. The data obtained will allow predicting the likely changes in the health status of students and conduct appropriate corrective and rehabilitation measures in order to ensure the success of educational activities while minimizing their "physiological cost."
\end{abstract}

Keywords: somatic health, students, motor mode, organism, functional state

\section{INTRODUCTION}

Health is a scientific, practical, and global issue. This is evidenced by the efforts of the World Health Organization, problematic international conferences, as well as the National Security Concept of the country. However, at present, the health of schoolchildren has deteriorated significantly. The deterioration of the health of schoolchildren is due to the influence of numerous factors of a socio-economic and environmental nature, the mass introduction of hygienically untested copyright programs into educational institutions.

Undoubtedly, a post-industrial society requires the development of a high-efficiency mind that assimilates advanced cognitive paradigms and knowledge systems. Recent studies show that innovations in the content and technology of the educational process are not always adequate for the functional and adaptive capabilities of the child's body [3, 5]. The introduction of innovative teaching technologies in a comprehensive school is usually accompanied by an intensification of the educational process, an increase in mental and emotional stress [9].

The individual life of an organism is a process of continuous adaptation to a changing environment in order to achieve adequate interaction with the outside world. Children have their specifics of adaptation. The child's body is in the process of continuous growth and development. The child has lowered the threshold of external differentiation, which makes him more vulnerable to environmental influences. Therefore, training in experimental, developmental programs often leads to functional disorders and diseases [7]. It is known that painful symptoms are preceded by more subtle shifts that are not subjectively perceived in the initial stages of occurrence. Such shifts affect the homeostatic regimes, regulatory systems, the psychoemotional sphere, and the autonomic system of the body. As a result, students in the learning process acquire a wide range of various diseases and functional pathologies. Moreover, there is a violation of the foundations of social adaptation. Schoolchildren have an active-negative attitude towards learning.

In order to solve the problem of preserving and strengthening the health of students, it becomes necessary to carefully study the interaction and mutual influence of age development and learning experience. It is necessary to disclose early functional disorders in schoolchildren and to identify individuals with non-specific (prenosological) conditions of the body. Particular attention is necessary for the conditions of healthy children since, during overloads, their level of adaptive capabilities of the body is provided due to tension or overstrain of regulatory mechanisms against the background of changes in homeostatic modes and decrease inefficiency.

The physiological approach to assessing health corresponds to the classification of body conditions adopted today [6], which includes:

- conditions with sufficient functional (adaptive) reserve;

- $\quad$ pre-nosological conditions in which adverse changes in the body's work are compensated by a higher than healthy tension of regulatory systems;

- $\quad$ premorbid states, which are characterized by a decrease in the functional reserves of the body, overstrain of regulatory systems;

- conditions of failure of adaptation, decompensation, development of diseases.

Mass screening studies of the functional state of the body are necessary for identifying groups of children at risk of a decline in health. These studies will allow creating a holistic view of the individual health profile of the child.

The most significant deviations in the system should be considered as stress at various levels, which must be 
corrected by various measures. These circumstances require fundamentally new approaches. The approaches used should take into account the fundamental biological characteristics of the body. These characteristics are general regulatory and adaptive capabilities, functional (adaptive) reserve, and the state of compensatory mechanisms [4].

From the standpoint of health protection, an important place is taken by the organization of physical education. For the upbringing of the child, it is necessary to use new physical education technologies in the context of innovative educational programs. New fitness technologies are aimed at improving the functional state of the body. New technologies make it possible to provide homeostasis of physiological systems with functional resources, which means that each child can maintain a sufficiently high level of physical health throughout the entire period of schooling $[8,10]$.

In terms of what we said, we conducted a comprehensive study of the impact of innovative training programs and an extended motor regime on the functional state of the body and the health of students.

\section{METHODS AND MATERIALS}

The studies conducted in a longitudinal mode took part: students in grades 2-6, studying in the primary school according to the system of developing education L.V. Zankova, and in grades 5-6 at the gymnasium school under the traditional motor regime ( 2 physical education lessons per week) with an annual volume of 68 hours. During the period of study in elementary school (from 1st to 3rd grade), these students received sanatorium-compensatory treatment at the sanatorium once a year. Parallel studies were conducted with students of grades 2-6 who studied according to a similar educational program with extended motor mode. The advanced motor mode is based on the improved daily performance of physical exercises, with a total annual amount of 170 hours. The fitness model was built based on the traditional system with priority training and fitness focus.

The expansion of the motor regime was supposed to establish the optimal balance between the static and dynamic components in the regime of a child's day in the conditions of using intensive educational technologies (the educational system of L.V. Zankov, school-gymnasium). The purpose of these measures is to reduce fatigue and maintain favorable dynamics in the health status of students throughout the entire period of study.

The control group consisted of students in grades 2-6 who studied according to the traditional educational system with two physical education lessons per week with a priority educational orientation.

G.L. Apanasenko proposed assessment of somatic health levels, assessment systems [1]. Evaluation systems are based on a set of clinical and physiological indicators: correspondence of body weight to its length, power index, life index, Robinson index, or double product, Ruthier index. The complex of clinical and physiological indicators allows a certain extent characterizing the level of somatic and physiometric development, aerobic energy production, reactivity, and fitness of the cardiovascular system of the child's body. An assessment of the individual and corporate health of school children was carried out based on individual medical records and the conclusion of a pediatrician.

The survey was conducted twice a year - in the fall and spring in the middle of 1 and 4 quarters. It is during these periods that a reaction to training loads is observed an optimal level of adaptation to the middle of the first quarter is formed. The maladaptation develops in the fourth quarter in the case of irrationally constructed training sessions.

The norm was taken as a marker, the expression of which is the range of variations of various indicators, which preserves the rationality of the functional manifestations of the organism as a whole, and it is individual physiological systems.

\section{RESULTS}

A comprehensive analysis of the level of somatic health was carried out in the study of somatic health of students in the conditions of identical innovative educational programs and various regulated motor modes. The analysis showed that students in grades 2-6 do not achieve a "safe level" of health, i.e., the level at which the predicted incidence rates are 0 (Table 1,2$)$. Whereas according to the results of the clinical examination, the number of practically healthy children (health group I) was $17 \%$ in the innovative class with the traditional motor regime in primary school and $8 \%$ in the gymnasium, and in the innovative class with the extended motor regime $-24 \%$ throughout the study period. This data means that the results of a medical examination do not reveal prenosological health disorders.

At the same time, some patterns were discovered that minor changes to most of the integral functional indicators. Students in elementary school had a relatively lower level of somatic health. In particular, during the second and third years of schooling, boys' somatic health was at a much lower level than during the period of training at the middle level of the school. At the same time, in the class of developing education with the extended motor regime, the boys had the lowest points for the entire period of the examination (except for the spring of the 5th grade) (Table 1). It becomes clear that the physiological "price" for mastering innovative programs within the 5-hour weekly volume of physical activity was relatively high for this contingent of children, and excessive spending of "reserves" of the body took place. Adaptation to an innovative educational environment was due to a relatively high voltage of the regulatory mechanisms and body systems that provide homeostasis. As a result, the range of adaptability narrowed, there was a risk of failure of adaptation. These processes can lead to a decrease in the activity of various functions, a radical restructuring of the morphofunctional substrate. As a result, the body's ability to respond more subtly and effectively to the external environment, especially in an emergency, is lost. 
Table 1 Levels of somatic health of boys in conditions of innovation (L.V. Zankov system, gymnasium) and traditional training systems and various volumes of motor activity

\begin{tabular}{|c|c|c|c|c|c|c|c|c|c|c|c|}
\hline \multirow[b]{2}{*}{ 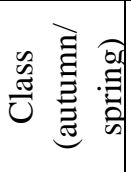 } & \multirow[b]{2}{*}{ 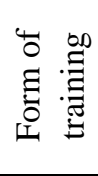 } & \multicolumn{10}{|c|}{ Indicators $(\mathrm{M} \pm \mathrm{m})$} \\
\hline & & $\begin{array}{l}\text { Life index, } \\
\mathrm{ml} / \mathrm{kg}\end{array}$ & $\stackrel{\mathscr{0}}{\stackrel{\Xi}{0}}$ & $\begin{array}{c}\text { Power index, } \\
\%\end{array}$ & $\stackrel{\mathscr{\Xi}}{\circ}$ & $\begin{array}{l}\text { Robinson Index, } \\
\text { conv. units }\end{array}$ & : & $\begin{array}{l}\overrightarrow{7} \\
\frac{00}{2} \\
3\end{array}$ & $\begin{array}{l}\text { Roufier Index, } \\
\text { conv. units }\end{array}$ & 苛 & $\begin{array}{c}\text { Somatic } \\
\text { health, } \\
\text { points }\end{array}$ \\
\hline \multirow{3}{*}{$\begin{array}{c}\text { 2nd } \\
\text { grade/ } \\
\text { autumn }\end{array}$} & EMM & $44.7 \pm 1.5$ & 0 & $42.5 \pm 2.9$ & 0 & $87.5 \pm 2.3$ & 1 & 0 & $19.0 \pm 0.9$ & -6 & -5 \\
\hline & TMM & $46.1 \pm 2.2$ & 0 & $39.7 \pm 1.7 *$ & 0 & $88.9 \pm 3.2$ & 1 & 0 & $9.3 \pm 1.1 * * *$ & 0 & 1 \\
\hline & TR & $48.7 \pm 4.0 *$ & 0 & $52.3 \pm 3.8 * * *$ & 2 & $113.9 \pm 6.0 * * *$ & 0 & 0 & $12.2 \pm 0.8 * *$ & -4 & -2 \\
\hline \multirow{3}{*}{$\begin{array}{l}\text { 2nd } \\
\text { grade/ } \\
\text { Spring }\end{array}$} & EMM & $* * 40.8 \pm 3.1$ & 0 & $* * 38.2 \pm 4.1$ & 0 & $88.9 \pm 2.9$ & 1 & 0 & $17.2 \pm 1.5$ & -6 & -5 \\
\hline & TMM & $* * 51.4 \pm 2.8 * * *$ & 1 & $* * 45.9 \pm 5.7 * *$ & 1 & $* * * 72.2 \pm 4.2 * * *$ & 3 & 0 & $8.4 \pm 0.8 * * *$ & 0 & 5 \\
\hline & TR & $50.0 \pm 4.1$ & 0 & $52.3 \pm 3.1 * * *$ & 2 & $* * * 85.1 \pm 1.9$ & 2 & 0 & $11.7 \pm 0.7 * *$ & -4 & 0 \\
\hline \multirow{3}{*}{$\begin{array}{c}\text { 3rd } \\
\text { grade/ } \\
\text { autumn }\end{array}$} & EMM & $42.3 \pm 1.3$ & 0 & $* * * 54.1 \pm 1.3$ & 2 & $* * 96.9 \pm 2.0$ & 1 & 0 & $* * 12.5 \pm 1.2$ & -4 & -1 \\
\hline & TMM & $* * 40.6 \pm 1.4$ & 0 & $* * * 57.2 \pm 6.1 *$ & 2 & $* * 78.4 \pm 1.9 * * *$ & 2 & -1 & $* * 12.0 \pm 0.9$ & -4 & -1 \\
\hline & TR & $51.1 \pm 2.5 * * *$ & 1 & $* * 58.5 \pm 2.9 * *$ & 2 & $86.2 \pm 5.7 * * *$ & 1 & 0 & $13.6 \pm 1.2$ & -4 & 0 \\
\hline \multirow{3}{*}{$\begin{array}{c}\text { 3rd } \\
\text { grade/ } \\
\text { Spring }\end{array}$} & EMM & $* * 48.1 \pm 2.9$ & 0 & $* * 47.9 \pm 3.4$ & 1 & $* * 89.2 \pm 3.4$ & 1 & 0 & $* 10.3 \pm 0.9$ & -4 & -2 \\
\hline & TMM & $* * 51.5 \pm 3.1 *$ & 1 & $* 54.7 \pm 2.2$ & 2 & $* * 71.4 \pm 4.5 * * *$ & 3 & -1 & $* 10.8 \pm 0.9$ & -4 & 1 \\
\hline & TR & $* 49.7 \pm 0.1$ & 0 & $* * * 47.0 \pm 3.8$ & 1 & $* 83.3 \pm 3.7 * *$ & 2 & -1 & $14.6 \pm 1.1 * *$ & -4 & -2 \\
\hline \multirow{3}{*}{$\begin{array}{c}\text { th } \\
\text { grade/ } \\
\text { Spring } \\
\end{array}$} & EMM & $* * * 62.3 \pm 0.5$ & 2 & $* * * 58.7 \pm 5.7$ & 2 & $90.9 \pm 2.7$ & 1 & -2 & $8.2 \pm 1.4$ & 0 & 3 \\
\hline & TMM & $61.9 \pm 7.1$ & 2 & $* * * 67.2 \pm 1.9$ & 4 & $* * * 85.3 \pm 1.9 * *$ & 2 & 0 & $* 7.9 \pm 1.2$ & 0 & 8 \\
\hline & TR & $* * 58.5 \pm 1.2 * *$ & 2 & $* * 59.4 \pm 2.0$ & 2 & $* * * 74.5 \pm 2.1 * * *$ & 3 & -1 & $15.1 \pm 0.8 * *$ & -6 & 0 \\
\hline \multirow{3}{*}{$\begin{array}{c}\text { 6th } \\
\text { grade/ } \\
\text { autumn }\end{array}$} & EMM & $* * 56.0 \pm 2.2$ & 2 & $50.7 \pm 5.5$ & 2 & $* * 86.0 \pm 1.2$ & 1 & -1 & $10.4 \pm 0.7$ & -4 & 0 \\
\hline & TMM & $50.7 \pm 9.2$ & 1 & $65.9 \pm 6.9 * * *$ & 4 & $83.1 \pm 2.9 *$ & 2 & -1 & $* * 12.1 \pm 0.9 *$ & -4 & 2 \\
\hline & $\mathrm{TR}$ & $* 55.8 \pm 1.8$ & 2 & $59.6 \pm 3.2 * *$ & 2 & $* * * 107.8 \pm 2.9 * * *$ & 0 & 0 & $* 12.2 \pm 1.0$ & -4 & 0 \\
\hline \multirow{3}{*}{$\begin{array}{c}\text { 6th } \\
\text { grade/ } \\
\text { Spring }\end{array}$} & EMM & $56.0 \pm 5.7$ & 2 & $* * * 60.0 \pm 4.4$ & 2 & $* * 94.3 \pm 3.5$ & 1 & -1 & $11.5 \pm 0.9$ & -4 & 0 \\
\hline & TMM & $* * 64.1 \pm 3.5 * * *$ & 2 & $* * * 85.9 \pm 6.2 * *$ & 4 & $* * * 104.4 \pm 1.9 * *$ & 0 & 0 & $12.7 \pm 1.0$ & -4 & 2 \\
\hline & TR & $55.6 \pm 4.5$ & 2 & $62.2 \pm 2.1$ & 3 & $* * * 94.8 \pm 2.7$ & 1 & 0 & $14.1 \pm 0.6^{* *}$ & -4 & 2 \\
\hline
\end{tabular}

Note: (left) * - significance of differences within the same class at the beginning and end of the year: * - at $\mathrm{p}<0.05 ; * *-$ at $\mathrm{p}<0.01$; $* * *$ - at $\mathrm{p}<0.001$; (right) * - significance of differences between boys from a class with extended motor mode (EMM), traditional motor mode (TMM) and traditional form of education (TR): * - at p <0.05; ** - at p <0.01; *** - at $\mathrm{p}<0.001$.

The third year of study is one of the essential nodal periods in the child's life. By this period, the development of mechanisms of long-term adaptation strongly determines both the process of successful learning and the further course of the somatic and sexual development of the child. This circumstance is significant to consider since this period is critical for the development of adaptive and reproductive functions of the body. There is a dynamics of deterioration in the level of somatic health by the end of the 3rd grade in boys from the innovative class with extended motor mode. This dynamic indicates a decrease in the compensatory-reserve capabilities and the prediction of the disease development possibility in the future.

It should be emphasized that a similar nature of adaptive changes was observed in the 3rd grade and among boys from a class with a traditional form of education (Table 1). Moreover, low levels of somatic health were primarily due to the results of the Ruthier test, used for the integrated assessment of the adaptive capabilities of the cardiovascular system and the health of the body as a whole.
In general, according to Ruthie test, the boys' conditions performance was assessed as "mediocre" or "weak." This rating is set independently of the educational system and the mode of motor activity of children. A higher level of somatic health was observed in boys who studied in an innovative class with a traditional motor regime. Boys with a traditional motor regime were compared with their peers from the innovative class with an extended motor regime and with boys from a class with a traditional form of education. Traditional motorized boys showed a tendency to increase somatic health by the end of each school year due to improved indicators of life index, strength index $(\mathrm{p}<0.01)$ and Robinson index $(\mathrm{p}<0.001)$. In addition, this contingent of students recorded the best performance indicators of the cardiovascular system under the Roufier test. So, if we consider the indicators of boys who studied under the program of L.V. Zankova with extended motor mode, by the end of the 2nd year of schooling, the performance of these boys can be assessed as "unsatisfactory." The performance of boys with a traditional form of education can be assessed as "weak." The performance of boys from 
the Zankovsky class with the traditional motor mode, the performance can already be assessed as "satisfactory" (Table 1). Intense mental activity is a rather robust mobilization and activating factor in the processes of growth, development, and adaptation of the organism, and the expansion of its functional capabilities. Unless, of course, the intellectual and emotional stress does not go beyond the capabilities of the individual. For example, the summing up volume of high mental and physical stress in the day regimen of boys from the Zankovsky class with extended motor regime gives, as it is not paradoxical, the opposite negative effect. The more dramatically the magnitude of the parameters of the situation in which it is necessary to adapt, the more intense the regulatory systems are for boys. Such a dynamically recurring adaptive state of the body is characterized by maintaining a high level of tension of regulatory systems and a violation of the conjugation between indicators of somatic development and functional parameters to a greater extent. The data allow classifying them as a "risk group" since a disharmonious developing child has a higher predisposition to fatigue, overwork, and disease.

Table 2 Levels of somatic health of girls in conditions of innovation (L.V. Zankov system, gymnasium) and traditional educational systems and various volumes of motor activity

\begin{tabular}{|c|c|c|c|c|c|c|c|c|c|c|c|}
\hline \multirow{2}{*}{ 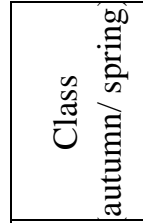 } & \multirow{2}{*}{ 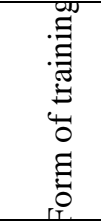 } & \multicolumn{10}{|c|}{ Indicators $(\mathrm{M} \pm \mathrm{m})$} \\
\hline & & $\begin{array}{l}\text { Life index, } \\
\mathrm{ml} / \mathrm{kg}\end{array}$ & . & $\begin{array}{c}\text { Power } \\
\text { index,\% }\end{array}$ & 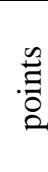 & $\begin{array}{l}\text { Robinson Index, } \\
\text { conv. units }\end{array}$ & $\stackrel{\mathscr{\Xi}}{\circ}$ & $\begin{array}{l}\text { Roufier } \\
\text { Matching } \\
\text { weight to } \\
\text { length }\end{array}$ & $\begin{array}{c}\text { Roufier } \\
\text { Index, conv. } \\
\text { units }\end{array}$ & 䒿 & $\begin{array}{c}\text { Уp } \\
\text { Somatic } \\
\text { health, } \\
\text { points }\end{array}$ \\
\hline \multirow{3}{*}{$\begin{array}{l}\text { 2nd } \\
\text { grade/ } \\
\text { autumn }\end{array}$} & EMM & $45.9 \pm 3.1$ & 1 & $51.2 \pm 3.9$ & 3 & $84.9 \pm 3.0$ & 2 & 0 & $17.8 \pm 1.2$ & -6 & 0 \\
\hline & TMM & $42.9 \pm 2.5$ & 0 & $39.4 \pm 3.2^{* * * *}$ & 0 & $79.6 \pm 2.9 * *$ & 2 & -1 & $9.0 \pm 0.7 * * *$ & 0 & 1 \\
\hline & TR & $40.4 \pm 1.7 *$ & 0 & $41.1 \pm 1.1 * * *$ & 1 & $104.5 \pm 4.6^{* * *}$ & 0 & 0 & $12.8 \pm 0.6^{* *}$ & -4 & -3 \\
\hline \multirow{3}{*}{$\begin{array}{l}\text { 2nd } \\
\text { grade/ } \\
\text { Spring }\end{array}$} & EMM & $* * 40.8 \pm 1.3$ & 0 & $50.3 \pm 2.8$ & 1 & $* * * 67.4 \pm 6.6$ & 4 & -1 & $* 14.0 \pm 0.9$ & -4 & 0 \\
\hline & TMM & $* 44.5 \pm 0.2 *$ & 0 & $* * 46.9 \pm 2.7 *$ & 2 & $* * 72.2 \pm 4.9 * *$ & 3 & 0 & $9.1 \pm 3.2 * *$ & 0 & 5 \\
\hline & $\mathrm{TR}$ & $* * 45.0 \pm 2.1 *$ & 0 & $* * 46.3 \pm 4.1 *$ & 2 & $* * * 84.6 \pm 5.9 * * *$ & 2 & 0 & $13.4 \pm 1.1$ & -4 & 0 \\
\hline \multirow{3}{*}{$\begin{array}{l}\text { 3rd } \\
\text { grade/ } \\
\text { autumn }\end{array}$} & EMM & $39.7 \pm 2.4$ & 0 & $48.8 \pm 5.8$ & 2 & $* * * 94.1 \pm 2.2$ & 1 & -1 & $12.6 \pm 0.8$ & -4 & -2 \\
\hline & TMM & $* * 40.4 \pm 2.6$ & 0 & $* * 38.8 \pm 1.6 *$ & 0 & $71.4 \pm 5.9 * * *$ & 3 & -1 & $* * 15.6 \pm 0.6 *$ & -6 & -4 \\
\hline & $\mathrm{TR}$ & $45.2 \pm 1.5 * *$ & 0 & $45.8 \pm 4.2 *$ & 2 & $* 79.5 \pm 3.5 * * *$ & 2 & -1 & $14.3 \pm 1.1 *$ & -4 & -1 \\
\hline \multirow{3}{*}{$\begin{array}{l}3 \text { rd } \\
\text { grade/ } \\
\text { Spring }\end{array}$} & EMM & $41.9 \pm 2.6$ & 0 & $48.8 \pm 6.7$ & 2 & $92.7 \pm 4.0$ & 1 & -1 & $10.3 \pm 0.8$ & -4 & -2 \\
\hline & TMM & $42.0 \pm 2.5$ & 0 & $39.6 \pm 2.6^{* * *}$ & 0 & $72.7 \pm 6.6 * * *$ & 3 & -1 & $13.2 \pm 1.1^{*}$ & -4 & -2 \\
\hline & TR & $* 49.4 \pm 2.9 * * *$ & 1 & $44.7 \pm 3.9 * *$ & 1 & $* * * 105.3 \pm 5.9 * * *$ & 0 & 0 & $15.4 \pm 0.8 * *$ & -6 & -4 \\
\hline \multirow{3}{*}{$\begin{array}{l}5 \text { th } \\
\text { grade/ } \\
\text { Spring }\end{array}$} & EMM & $48.7 \pm 4.7$ & 1 & $50.1 \pm 6.2$ & 2 & $92.4 \pm 4.4$ & 1 & 0 & $9.2 \pm 0.9$ & 0 & 4 \\
\hline & TMM & $49.7 \pm 7.3$ & 1 & $* * * 51.4 \pm 1.9$ & 3 & $* * * 90.6 \pm 2.7$ & 1 & 0 & $* * 17.2 \pm 1.4 *$ & -6 & -1 \\
\hline & TR & $52.0 \pm 1.2 *$ & 2 & $45.9 \pm 3.6^{* *}$ & 1 & $* * * 84.6 \pm 2.8 * *$ & 2 & 0 & $14.9 \pm 0.8 * *$ & -6 & -1 \\
\hline \multirow{3}{*}{$\begin{array}{l}\text { 6th } \\
\text { grade/ } \\
\text { autumn }\end{array}$} & EMM & $* 44.8 \pm 4.1$ & 0 & $50.5 \pm 4.0$ & 3 & $* * * 76.5 \pm 2.8$ & 2 & -1 & $* * 15.2 \pm 1.0$ & -6 & -2 \\
\hline & TMM & $48.7 \pm 2.5 *$ & 1 & $* 55.6 \pm 5.9 * *$ & 4 & $* * * 103.2 \pm 2.9 * * *$ & 0 & -1 & $18.4 \pm 1.6$ & -6 & -2 \\
\hline & TR & $53.2 \pm 2.6 * * *$ & 2 & $49.1 \pm 2.7$ & 2 & $* * 93.1 \pm 3.8 * * *$ & 1 & 0 & $14.6 \pm 1.1$ & -6 & -1 \\
\hline \multirow{3}{*}{$\begin{array}{l}\text { 6th } \\
\text { grade/ } \\
\text { Spring }\end{array}$} & EMM & $46.4 \pm 3.8$ & 1 & $52.3 \pm 2.8$ & 3 & $* * 89.1 \pm 4.6$ & 1 & -1 & $* 12.8 \pm 0.7$ & -4 & 0 \\
\hline & TMM & $* 45.0 \pm 3.5$ & 0 & $* 59.2 \pm 6.8 * *$ & 4 & $* * 111.2 \pm 5.9 * * *$ & 0 & 0 & $* 16.0 \pm 1.3 * *$ & -6 & -2 \\
\hline & $\mathrm{TR}$ & $55.3 \pm 1.9 * * *$ & 2 & $49.2 \pm 4.2 *$ & 2 & $* * * 103.2 \pm 6.7 * * *$ & 0 & -1 & $14.5 \pm 0.9$ & -6 & -3 \\
\hline
\end{tabular}

Note: (left) $*$ - significance of differences within the same class at the beginning and end of the year: $*-$ at $\mathrm{p}<0.05 ; * *-$ at $\mathrm{p}<0.01$; $* * *$ - at $\mathrm{p}<0.001$; (right) $*$ - significance of differences between girls from the class with extended motor mode (EMM), traditional motor mode (TMM) and traditional form of training (TR): $*_{-}$at $\mathrm{p}<0.05 ; * *-$ at $\mathrm{p}<0.01 ; * * *-$ at $\mathrm{p}<0.001$.

In the 6th grade, a significant decrease in the level of somatic health was noted. This data, due to the beginning of puberty. This period of child growth is intersystem, and intrasystem heterochrony intensifies. Moreover, the imbalance of most functions occurs.

The progressive deterioration in the level of somatic health in the 6th grade against the backdrop of deterioration in adaptive capabilities and a decrease in useful resources allows considering this period of study at a school for boys as a critical period for the formation of diseases. To develop effective preventive measures, the pediatrician's conclusion on the state of health and appropriate analysis of the structure of functional and chronic diseases based on the data of the clinical examination is significant.

It should be emphasized that all the above considerations are entirely valid for girls. In particular, in girls from an innovative class with a traditional motor 
regime, trained in conditions of an increased volume of the mental and low volume of physical activity, starting from the 3rd and 6th grade, the level of somatic health was stably in the negative range (Table 2). It must be assumed that the total amount of all physiological and mental costs of the body for a mental activity with a limited mode of motor activity is excessively high for girls. Redundancy is manifested despite the school's health activities. The danger is that the resulting overstrain of psychophysiological mechanisms can lead to disruption of the processes of growth and development, which is a risk factor for the development of diseases. Although, according to individual authors, these changes do not yet cause disease, they reduce the adaptive capabilities of the body. They are combined into the concept of prenosological and premorbid conditions. However, there are works $[2,9]$ that indicate a significant prevalence of chronic pathology among groups of children with low somatic health.

Girls from the innovative class with an extended motor regime developed a different nature of changes in the level of somatic health. Their high physical development was accompanied by an increase in the degree of adaptation to vigorous physical exertion, an expansion of the functional capabilities of the respiratory system, and an increase in the relative strength of the hand (Table 2). Presumably, regulated physical education classes ( 5 hours a week) in the context of innovative programs have a direct impact on ways to increase adaptive potential. In this mode, a fundamentally different neuroendocrine and energy organization of growth processes arises in the girls' body. The functional reserve boundaries of the body are expanding, and its development is shifting to a higher level. High values of maximum aerobic abilities and working capacity in this group of children also indicate the development of the energy potential of the body. The data show that there are prerequisites for a good state of somatic health and a reduction in the risk of disease. All this dictates the need to increase the effectiveness of sports and fitness technologies aimed at increasing the physical development, resistance, and endurance of the female body.

\section{CONCLUSION}

In general, the results of a comprehensive rapid assessment of the level of somatic health were carried out according to the method of G.L. Apanasenko. An analysis of the data allows concluding the unfavorable dynamics in the state of health of schoolchildren who studied in the conditions of application of intensive educational technologies. The presence of the identified data is confirmed using physiological methods of the risk contingency. At the same time, the bulk of students leave the "safe zone" of health. This situation is dangerous because, with an inadequate daily regimen, a pathological process can develop in a child. Against this background, the intensification of the educational process can cause a deterioration in the biological reliability of the body, change the adaptation strategy. To a greater extent, this threatens the body of boys. It becomes clear that when choosing an educational model, it is necessary to take into account the individual and age-specific characteristics of the adaptation of children and adolescents. The training load in intensity and volume should be adequate for the growth of the level of functioning with sufficient functional reserve.

The educational process should be health-saving. However, for this, there should be a reasonably accurate idea of the somatic, vegetative, psychophysiological, motor, and energy status of students in the context of various programs and methods of educational activity. Teacher activities should include familiarization with the results of medical examinations, psychophysiological and physiological-hygienic testing, and take them into account in educational work. A departure from the traditional system of physical education is needed, as well as a search for new sports and fitness technologies. These issues should be addressed primarily based on specific guidelines.

\section{REFERENCES}

[1] G.L. Apanasenko, Diagnosis of individual health, Valeology 3 (2002) 27-31.

[2] G.L. Apanasenko, V.K. Kozakevich, L.D. Korovin, The level of somatic health, its relationship with physical development and prediction of the incidence of adolescents, Valeology 1 (2002) 19-24.

[3] E.N. Weiner, Ensuring the health of students and teachers in an educational institution, Reg. Ed.: Current Trends 2(20) (2013) 52-60.

[4] E.M. Kazin, I.A. Sviridova, A.I. Fedorov, T.I. Scherer, Health assessment based on the integration of psychological, pedagogical and medical-physiological approaches, Valeology 2 (2016) 40-43.

[5] A.V. Shakhanova, N.N. Khasanova, T.V. Glazun, Model of ontogenetic development of children and adolescents in the conditions of variable educational environments, Russ. Physiolog. J. 8 (2004) 415.

[6] R.M. Baevsky, A.P. Berseneva, Pre-nosology diagnostics, Cardiometry 10 (2017) 55-63.

[7] O. Kamaev, E. Proskurov, V. Potop et al., Factors that influence somatic health of 10-11-year-old schoolchildren at the beginning and end of an academic year, J. of Phys. Ed. and Sport 17(1) (2017) 407-413.

[8] E.V. Khromin, A.V. Kolychev, N.G. Radostev, Integration of basic and post-secondary physical education as a basis of development of mass physical culture and children and youth sport at the municipal level, Teoriya I Praktika Fizicheskoy Kultury 12 (2013) 3-8.

[9] I.E. Shtina, S.L. Valina, O.Yu. Ustinova et al., Peculiarities of autonomous and thyroidal state in 
school children under the different intensity of the educational process, Gigiena i Sanitariya 98(2) (2019) 183-188.
[10] F. Trudeau, R.J. Shephard, Physical education, school physical activity, school sports and academic performance, Int. J. of Behavioral Nutrit. and Phys. Activity 10 (2008) 5 . 